\title{
A QUALIDADE DE VIDA DO PROFESSOR EM UM CENTRO UNIVERSITÁRIO DE BARRA DO GARÇAS-MT
}

\author{
THE LIFE QUALITY OF THE PROFESSOR IN A UNIVERSITY CENTER \\ IN BARRA DO GARÇAS-MT
}

\author{
Marcela Silvéria Araújo ${ }^{1}$ \\ Lívia de Oliveira Teixeira Dias Carvalho² \\ Vera Lúcia Macedo de Oliveira Teixeira ${ }^{3}$
}

\begin{abstract}
RESUMO: Os indivíduos e as organizações formam uma parceria de mão dupla, uma vez que estes passam a maior parte de suas vidas no contexto organizacional. O mundo moderno do trabalho tem passado por transformações que afetam toda a sociedade, inclusive a categoria dos professores. O termo qualidade de vida representa um desafio para muitas pessoas por garantir condições de vida que englobam a saúde física, mental e espiritual, além de equilíbrio entre o lado pessoal e profissional. Diante desse contexto, procurando desenvolver o tema qualidade de vida no trabalho, esta pesquisa busca a resolução da seguinte problematização: em que medida as multifunções influenciam a qualidade de vida do professor em uma instituição de ensino superior privada? Neste sentido, foi realizado um estudo sobre a Qualidade de Vida no Trabalho (QVT) com os professores de um Centro Universitário em Barra do Garças-MT. Buscou-se identificar o perfil profissional desses professores, o significado atribuído pelos docentes à QVT, o tempo de exercício na docência, as multifunções e a carga horária semanal de trabalho. Tratase de uma pesquisa bibliográfica, cujo método de abordagem utilizado foi o dedutivo, levando em conta os critérios quantitativos e qualitativos, norteado pela pesquisa de campo semiestruturada. A partir de entrevistas realizadas com docentes (homens e
\end{abstract}

\footnotetext{
${ }^{1}$ Especialista em Gestão de Pessoas. Pós Graduanda em Docência no Ensino Superior. Bacharel em Administração com Habilitação em Gestão da Informação pela Faculdade de Ciências Jurídicas e Sociais Aplicadas do Araguaia - FACISA. Professora e Coordenadora do Recursos Humanos do Centro Universitário UniCathedral de Barra do Garças. Email:marcelasilveria@hotmail.com.

2 Mestranda em Educação na Pontifícia Universidade Católica de Goiás-PUC GO. Bolsista Capes e com pesquisa na linha de Teorias da Educação e Processos Educacionais. Psicóloga no Centro Universitário Unicathedral e Professora de Educação Infantil no Município de Barra do Garças-MT. Email: livia.carvalho86.psi@gmail.com.

3 Mestre em Educação - Pontifícia Universidade Católica de Goiás, Pedagoga, Especialista em Didática, Especialista em Docência no Ensino Superior, Professora do curso de Pedagogia do Centro Universitário UniCathedral de Barra do Garças-MT, Coordenadora Pedagógica do Colégio Cathedral. Email:vera.macedo@unicathedral.edu.br.
} 
mulheres), identificou-se que, o principal significado de QVT é ter condições adequadas à execução do trabalho.

PALAVRAS CHAVES: Professor. Qualidade de Vida. Globalização. Mundo do Trabalho.

ABSTRACT: The individuals and the organizations form a two-way partnership, as they spend most of their lives in the organizational context. The modern world of work has undergone transformations that affect the whole society, including the category of professors. The term life quality represents a challenge for many people because it guarantees living conditions that include physical, mental and spiritual health, as well as a balance between the personal and the professional side. In this context, seeking to develop the theme life quality at work, this research seeks the resolution of the following problematization: to what extent do multifunctions influence the life quality of professors in a private college institution? In this sense, a study on the Life Quality at Work (QVT) was carried out with the professors of a University Center in Barra do Garças-MT. It was aimed to identify the professional profile of these professors, the meaning attributed by teachers to QVT, the time spent in teaching, the multifunctions and the weekly workload. It is a bibliographic research, whose approach method used was the deductive one, taking into account the quantitative and qualitative criteria, guided by the semi-structured field research. From interviews with professors (men and women), it was identified that, the main meaning of QVT is to have adequate conditions to perform the work.

KEYWORDS: Professor. Life Quality. Globalization. World of Work. 


\section{INTRODUÇÃO}

No mundo contemporâneo dos negócios, cada vez mais se fala em resultados, lucros e competitividade. O capital intelectual torna-se o grande diferencial para as organizações atingirem seus objetivos estratégicos, todavia, o mercado de trabalho atravessa enormes modificações econômicas, sociais, políticas e culturais. Tendo como referência a cidade de Barra do Garças, um município brasileiro, localizado na Região Centro-Oeste, no estado de Mato Grosso, o qual é o oitavo município mais populoso, com população de 58099 habitantes, conforme a estimativa do IBGE, em 2014.

É um polo regional em Mato Grosso, sendo a principal cidade da região conhecida como Vale do Araguaia, nas proximidades da divisa com o estado de Goiás. É hoje considerada um polo Universitário que agrega várias instituições de ensino superior, com um campus da UFMT em Barra do Garças, aglomerando diversos jovens de municípios circunvizinhos. É uma grande porta de empregos para a população local, e, essas instituições, por sua vez, auxiliam no desenvolvimento do Município, gerando empregos e melhorando a sua economia. As Instituições de Ensino Superior têm sentido as transformações que estão ocorrendo no mundo do trabalho e isso tem influenciado a qualidade de vida no trabalho dos professores.

O presente projeto será desenvolvido por meio de uma pesquisa exploratóriodescritiva, de delineamento qualitativo. O estudo de caso, segundo a coleta de dados junto aos professores do Centro Universitário, campo dessa pesquisa, será por meio de uma entrevista semiestruturada e, para análise dos dados coletados, a técnica utilizada será a de análise de conteúdo. Alta performance, resultados, habilidades, competências, novas tecnologias e participações em inúmeras redes sociais são palavras citadas com muita frequência e que estão provocando um certo "corre-corre" no cenário das organizações, e um "alvoroço" interno nas pessoas, restando pouco tempo para olharem para dentro de si. Com isso, os profissionais iniciaram uma caminhada árdua e longa com o intuito de continuar alinhados às 
mudanças que, diariamente, são exigidas para que estejam sempre à frente no que diz respeito às novas informações, já que estar atualizado é uma necessidade inegável.

Tendo em vista o momento histórico marcado pela globalização e pela tecnologia, consequentemente, os estilos de vida tem se alterado e tais transformações trouxeram significativas mudanças ao desenvolvimento econômico e social do homem, só que, em alguns casos, tem atuado de forma negativa. Sobreviver nesta sociedade com uma realidade satisfatória, realizadora e relativamente independente não é uma tarefa fácil, afinal, o bem-estar físico e mental acabam sendo trocadas para que outras necessidades, tidas como básicas, sejam supridas.

A vida moderna e as exigências no âmbito do trabalho levam os indivíduos a, gradativamente, desenvolver algum tipo de distúrbio, uma vez que as atribuições diárias, a má alimentação, a falta de tempo para atividade física, o lazer, o pouco tempo para o descanso e o sono, acabam resultando em má qualidade de vida e, consequentemente, em estresse (MELEIRO, 2002, p. 12). Além disso, as condições de trabalho não têm sido as melhores, pois, de acordo com Nunes Sobrinho (2002), "o professor em sua prática pedagógica ainda tem de se adequar a condições de ensino adversas".

No mundo do trabalho, observa-se uma transformação nas organizações e em suas relações, nas quais surgem novas formas, tais como, o autônomo, o temporário, o trabalho terceirizado; relações estas que substituem as relações tradicionais de emprego. Tais modificações trazem em seu interior a exigência de redefinições das relações do trabalho e novos conflitos que procuram legitimar novas formas de representatividade dos trabalhadores e do próprio trabalho que terão seu impacto na profissão de docente. (COSTA, 2002, p. 21).

Para complementar esse impacto, as necessidades em qualificação profissional e constantes atualizações para lidar com os inúmeros meios tecnológicos e as exigências em publicações periódicas, resultam em uma obrigatoriedade do professor de ensino superior com o intuito de atender às constantes demandas de especialidades profissionais. Dentre os aspectos 
causadores de estresse entre docentes da Instituição pesquisada, destaque-se que o acúmulo de funções, uma vez que a grande maioria é formada por profissionais bacharéis que atuam em sua profissão por formação nas organizações e, vista como atividade complementar, concilia a prática docência. São vários os resultados colhidos pela maior aproximação entre a instituição de ensino superior e a prática cotidiana nas organizações.

A existência de profissionais que se dedicam simultaneamente à profissão de advogado, contador, administrador, engenheiro, enfermeiro, farmacêutico e à docência, além de ser um ponto de sinergia entre os dois campos, é também bastante valorizada, especialmente nas instituições de ensino superior privadas, que entendem a prática profissional como essencial para o exercício da docência. A multifunção para conciliar as demandas de cada função tem resultado compensador, e beneficia a IES, que pode dispor de um professor com vivência prática para compartilhar com seus alunos, e o próprio profissional, que leva para seu ambiente de trabalho novos conhecimentos e visões absorvidos no meio acadêmico.

Gerenciar o tempo, contudo, é o grande desafio. A dupla jornada resulta em uma rotina estressante, que inclui expediente em horário comercial no escritório, na empresa, no hospital, na farmácia e/ou na obra e ministrar aulas à noite, ou pela manhã, e atividades extras para preparo de aulas e correção de trabalhos. Não raro essas tarefas acabam tomando horas que deveriam ser de descanso, em fins de semana. O equilíbrio entre as duas funções nem sempre está na medida. Os docentes não têm tempo para cuidarem de si próprio e são quase que obrigados a enfrentar situações estressantes no seu cotidiano, na empresa e/ou Instituição de Ensino Superior onde atua, o que pode, em longo prazo, interferir na sua saúde física e mental.

A contribuição deste estudo vincula-se ao Departamento Pessoal de um Centro Universitário e o estudo certamente trará grandes conhecimentos para a vida profissional, tornando-se uma oportunidade viável para aplicabilidade dessa aprendizagem no desenvolvimento do $\mathrm{RH}$, servindo de contribuição para a Instituição, tendo em vista que a pesquisa será um indicador para melhorias das políticas de gestão de pessoas da IES. 
Diante do exposto, este estudo tem como objetivo identificar o perfil demográfico e profissional de professores de Ensino Superior em um Centro Universitário, bem como correlacionar o nível de qualidade de vida com a idade, o tempo de docência e a carga horária semanal de trabalho desses profissionais multifuncionais, que exercem diversas atividades simultaneamente.

\section{TRABALHO E A QUALIDADE DE VIDA}

O trabalho faz parte da vida do homem, mas para alguns, ele representa castigo, para outros apenas um meio de sobrevivência, outros o veem como um caminho de autorrealização. A Etimologia da palavra "trabalho" tem sua origem no vocábulo latino "TRIPALIU": denominação de um instrumento de tortura formado por três (tri) paus (paliu). Desse modo, originalmente, "trabalhar" significa ser torturado no tripaliu. (Dicionário Informal Online).

A palavra trabalho é originária do latim tripalium, que significa instrumento de tortura, usado na Roma antiga. Há mais de um milênio os gregos consideravam trabalho como qualquer atividade menor, inferior. Historicamente, em muitas culturas espalhadas pelo mundo, trabalho teve a conotação de escravidão. (MACHADO, 2012, p1).

Em tempos contemporâneos a ideia de castigo e sofrimento vinculado ao trabalho está perdendo o espaço. A interpretação de trabalho deve ser positiva, pois é uma atividade que exalta o homem e lhe dá a oportunidade de progredir na vida.

Ainda há muitas pessoas que veem o trabalho como um castigo imposto aos cidadãos, passam o tempo todo desmotivadas, esperando que algo aconteça para que elas comecem a melhorar. Seja qual for a atividade que executam, o sentido ao trabalho quem dá é a própria pessoa. Se o significado do trabalho for grandioso, ela comprometerá verdadeiramente com sua profissão. O filósofo Alain de Botton, autor do livro Os prazeres e desprazeres do trabalho, diz: "[...] que o trabalho, ao lado do amor, pode ser a nossa principal fonte de sentido na vida. Nós passamos maior 
parte do tempo no trabalho, sobra pouco tempo para outras atividades importantes como, lazer, saúde, estar com a família e amigos etc."

Como dizia Benjamin Franklin, o trabalho dignifica o homem. Essa frase evidencia o quanto é relevante o fato de se trabalhar e o quanto o trabalho é importante não somente para o sujeito, mas para a sociedade em geral. O trabalho, em sua prática é uma forma de concretização de sonhos, atingir suas metas e objetivos de vida e manifestação do potencial de cada indivíduo.

[...] O trabalho toma consideravelmente tempo das vidas e dos esforços das pessoas, que dele dependem para a subsistência e sucesso pessoal. Separar o trabalho da existência das pessoas é muito difícil, senão quase impossível, diante da importância e do impacto que o trabalho nelas provoca. Assim, as pessoas dependem das organizações nas quais trabalham para atingir seus objetivos pessoais e individuais. Crescer na vida e ser bem-sucedido depende de crescer dentro das organizações. [...] (CHIAVENATO, 2010, p. 04).

Para que a realização pessoal e execução do trabalho se mantenham em consonância, é essencial o conhecimento das condições relacionadas à promoção de bem-estar, assim como dos fatores que afetam direta ou indiretamente a saúde psíquica e/ou física e que possam ocasionar transtornos mentais ao trabalhador, e, assim, preveni-los e, consequentemente, favorecer o crescimento, tanto da pessoa e quanto da empresa.

\section{1 MOTIVAÇÃO E SATISFAÇÃO NO TRABALHO}

Há muito se sabe que satisfação e motivação profissional não estão necessariamente ligadas a salário. Talvez, exatamente por não existirem fórmulas que solucione tais problemas, existem tantos profissionais sem brilho nos olhos e infelizes com as carreiras profissionais.

Para Chiavenato, (2014, p. 237): os processos de recompensar "[...] as pessoas constituem os elementos fundamentais para o incentivo e a motivação dos funcionários, tendo em vista, de um lado, os objetivos organizacionais a serem 
alcançados e, de outro, os objetivos individuais a serem satisfeitos." Por essa razão, os processos de oferecer recompensas ocupam lugar de destaque entre os principais processos de gerir as pessoas nas organizações. Ainda, a partir desse autor, (Idem, 2003, p. 2), "a vida das pessoas depende intimamente das organizações e essas dependem da atividade e do trabalho daquelas."

$\mathrm{Na}$ sociedade moderna, as pessoas vivem sua rotina, assim como a vida pessoal, profissional, dentro das organizações. Nesse sentindo, o sucesso de toda empresa depende das pessoas, sejam colaboradores, clientes ou fornecedores, qualquer pessoa que desempenha um determinado papel.

Pessoas e organização formam, portanto, uma parceria de mão dupla; as pessoas passam maior parte de suas vidas trabalhando dentro de organizações. As organizações dependem das pessoas para atingirem seus objetivos organizacionais, e, já as organizações constituem para as pessoas um meio pelo qual elas podem alcançar muitos e variados objetivos pessoais com um mínimo de custo, de tempo, de esforço e de conflito, os quais não poderiam ser alcançados apenas através do esforço individual.

O clima organizacional é decorrente das percepções dos colaboradores sobre a empresa. A satisfação e motivação dos colaboradores impactam de forma significativa para um clima favorável. VERGARA (2000, p. 45), segundo o qual a motivação é intrínseca, ou seja, ninguém motiva ninguém. É a própria pessoa que se motiva ou não.

[...] O trabalho toma consideravelmente tempo das vidas e dos esforços das pessoas, que dele dependem para a subsistência e sucesso pessoal. Separar o trabalho da existência das pessoas é muito difícil, senão quase impossível, diante da importância e do impacto que o trabalho nelas provoca. Assim, as pessoas dependem das organizações nas quais trabalham para atingir seus objetivos pessoais e individuais. Crescer na vida e ser bem-sucedido depende de crescer dentro das organizações. (CHIAVENATO, 2010, p. 04).

É inquestionável que o trabalho seja uma questão primordial na vida do ser humano, influenciando fortemente sobre todas as outras áreas da vida. Há uma variante sobre as influências e motivações entre a vida e o trabalho; cada vez que a motivação é afetada negativamente na nossa vida ou ela sofre um abalo no trabalho, 
fazendo com que percamos as perspectivas de progressão e com que a satisfação diminua, consequentemente, a motivação na nossa vida também tem tendência a diminuir. Isso comprova que a motivação funciona como um grande potenciador da qualidade de vida e satisfação no trabalho.

A participação é o caminho natural para o homem exprimir sua
tendência inata de realizar, fazer coisas, afirmar-se a si mesmo
e dominar a natureza e o mundo. Além disso, sua prática
envolve a satisfação de outras necessidades não menos
básicas, tais como a interação com os demais homens,
autoexpressão, o desenvolvimento do pensamento reflexivo, o
prazer de criar e recriar coisas, e, ainda, a valorização de si
mesmo pelos outros. (BORDENAVE, 1995, p. 16).

A motivação pode ser definida como um propulsor que leva o homem a buscar novos desafios, induzindo-o a praticar novas ações. No entanto, a falta dela causa desinteresse pelo trabalho e faz do colaborador um mero repetidor de tarefas, limitando sua visão e desviando-o do processo em geral. Quando uma pessoa está desmotivada, o trabalho não rende, as horas demoram a passar, a proatividade é inexistente e falta assertividade. Sendo assim, a motivação no trabalho é um elemento essencial para o sucesso de uma organização.

O entusiasmo pessoal é fundamental para o desenvolvimento profissional contínuo; o profissional que se mantém motivado consigo tem muito mais comprometimento com sua profissão, pois possui, antes de tudo, um compromisso pessoal de crescimento e alcance de metas. Não é garantia que o clima organizacional proporcionará um ambiente que dê ânimo e motivação aos colaboradores, portanto, ser automotivado é um dos primeiros passos para sentir-se satisfeito no ambiente de trabalho. 


\section{QVT - SAÚDE, QUALIDADE DE VIDA E QUALIDADE DE VIDA DOS PROFESSORES}

A Organização Mundial de Saúde (OMS) define saúde não apenas como a ausência de doença, mas como a situação de perfeito bem-estar físico, mental e social. Contudo, um estado de completo bem-estar físico, mental e social, não consiste apenas na ausência de doença ou de enfermidade. Usufruir do melhor estado de saúde possível, constitui um dos direitos fundamentais de todo o ser humano, sem distinção de raça, de religião, de credo político, de condição econômica ou social. Para Silva e Marchi (1997), "a saúde é muito influenciada pelo estilo de vida, e este afeta diretamente a qualidade de vida". De acordo com os autores, viver com qualidade de vida é:

[...] saber manter o equilíbrio no dia-a-dia, procurando sempre melhorar o processo de interiorização de hábitos saudáveis, aumentando a capacidade de enfrentar pressões e dissabores e vivendo mais consciente e harmônico em relação ao meio ambiente, às pessoas e a si próprio. (MARCHI, 1997, p. 8).

Há algum tempo, a qualidade de vida tornou-se tão importante na sociedade, que as empresas começaram a se preocupar com a qualidade de vida que estavam oferecendo a seus funcionários. A gestão de recursos humanos contemporânea defende a utilização dos recursos humanos como elemento estratégico e fundamental no sucesso das organizações.

[...] o conceito de QVT envolve tanto os aspectos físicos e ambientais, como os aspectos psicológicos do local do trabalho. A QVT assimila duas posições antagônicas: de um lado, a reivindicação dos empregados quanto ao bem-estar de um lado, a reivindicação dos empregados quanto ao bem-estar e satisfação no trabalho; e, de outro, o interesse das organizações quanto aos seus efeitos potenciadores sobre a produtividade e a qualidade. (CHIAVENATO, 2004, p. 448). 
Qualidade de vida é a expressão utilizada para indicar as condições de vida de um ser humano, envolvendo vários âmbitos, como o bem físico, mental, psicológico e emocional, relacionamentos sociais, como família e amigos, e também saúde, educação e outros parâmetros que afetam a vida humana. Para Chiavenato (2004, p. 448), "a organização que quiser atender bem o cliente externo, ela não poderá esquecer de atender bem o cliente interno". Assim, a gestão da qualidade total nas organizações depende, inicialmente, da valorização e o bom uso do potencial humano. Consequentemente, depende de quão bem as pessoas se sentem trabalhando na organização.

A definição de Qualidade de Vida no Trabalho - QVT, adotada por Limongi França e Zaima (2002), "é o conjunto das ações de uma empresa que envolve a implantação de melhorias e inovações gerenciais, tecnológicas e estruturais no ambiente de trabalho". Já para Vieira (1990), "a QVT tem como objetivo central gerar uma organização mais humanizada para resultar dela uma relação entre capital e trabalho não conflitante, mas sim cooperativa". Apesar de não existir um consenso sobre o conceito de Qualidade de vida no trabalho (QVT), em 1950 surgiu a abordagem sociotécnica como um dos vários estudos empreendidos por um grupo de pesquisadores do Instituto Tavistock de Londres, sob a coordenação de Eric Trist, em que sinalizaram, pela primeira vez, a importância dos fatores psicológicos e sociais na dinâmica organizacional.

A qualidade de vida no trabalho pode ser definida como a busca do equilíbrio entre o psíquico, o físico e social, e o respeito às necessidades e limitações do ser humano, o que se espera resultar num crescimento pessoal e profissional, sem traumas; com isso, será afetado atitudes pessoais e comportamentais importantes para o rendimento pessoal e grupal, como a motivação para o trabalho, adaptabilidade a mudanças, criatividade e vontade de inovar. Uma solução para isso seria fazer com que as empresas pensassem mais em seus empregados, promovendo a Qualidade de Vida no Trabalho, para que possam ter produtividade e desempenho para suas empresas. No entanto, a problemática é que, nos dias atuais, algumas empresas não se preocupam em oferecer Qualidade de Vida aos seus funcionários e com isso eles não têm motivação para realizar um bom trabalho. 
Como estratégia para alcançar níveis elevados de qualidade e produtividade, as organizações necessitam de pessoas motivadas, participantes ativos nos trabalhos que executam e que sejam devidamente recompensadas por suas contribuições. A qualidade de vida dos colaboradores, sujeitos dessa pesquisa, é evidenciada como fator integrante para o alcance de resultados, neste caso, os empregados são vistos como parceiros da empresa, e não como meros recursos humanos. O objetivo é que sejam mantidos de forma harmoniosa aspectos como a integridade física, mental e social dos professores. Segundo a OMS (Organização Mundial de Saúde) "saúde emocional é um estado de bem-estar onde o indivíduo realiza suas próprias habilidades, lida com os fatores estressantes normais da vida, trabalha produtivamente e é capaz de contribuir com a sociedade". É preciso ter satisfação na vida. Ela é uma emoção que faz com que a pessoa sinta bem-estar, amor por si e pelos outros.

A motivação no trabalho é essencial para todo colaborador e em especial para o professor contemporâneo, trabalhar é mais do que uma necessidade, é o que promove o sustento do homem e, ao mesmo tempo, faz com que ele possa se sentir produtivo, útil e ativo perante a sociedade. O problema é quando o elevado acúmulo de funções desse profissional, começa a comprometer o tempo livre para cuidados com a vida pessoal, e, interfere no tempo para cuidados com a saúde, comprometendo a sua qualidade de vida no trabalho e fazendo com que as relações trabalho e qualidade de vida, não sejam tão harmoniosas. "A docência apresenta uma série de conteúdos cognitivos, efetivos e instrumentais que interferem na qualidade de vida dos professores" (MARTINEZ, VITTA e LOPES, 2009, p. 3). Com relação a esses conteúdos, é interessante citar como exemplo as longas jornadas de trabalho do empregado que são cada dia mais submetidos. Além disso, tem-se uma expansão de responsabilidades profissionais, já que o docente do ensino superior hoje não ministra somente aulas.

Segundo o estudo realizado por Martinez, Vitta e Lopes (2009, p. 06) "quanto maior a jornada de trabalho do docente, maiores os prejuízos na qualidade de vida, principalmente os referentes à relação com meio ambiente e aos fatores psicológicos". Como resultado, fica claro um docente sem tempo para cuidar de si, família, lazer, saúde, atividades domésticas, dentre outros problemas ligados ao 
exercício da profissão, como insatisfações, reclamações e desistências veladas ou assumidas.

\section{DADOS COLETADOS}

A pesquisa teve como sujeitos, professores do ensino Superior de um Centro Universitário localizado na cidade de Barra do Garças - MT, e a partir da divulgação dos seus resultados pretende-se contribuir com o melhor conhecimento sobre essa área. Participaram da pesquisa dezessete professores, sendo que cinco desenvolvem as suas atividades na graduação e na coordenação de curso e os outros doze atuam nos cursos de graduação em Administração, Agronegócio, Ciências Contábeis, Direito, Marketing, Pedagogia e também em pós-graduação. $O$ Corpo Docente da Instituição compreende os professores vinculados aos respectivos cursos ofertados na IES, abrangendo níveis hierarquizados de Doutor, Mestre e Especialista.

GRÁFICO 1: Tempo de exercício na docência do Ensino Superior.

\section{1 a 5 ANOS \\ 5 A 10 ANOS \\ MAIS DE 10 ANOS}

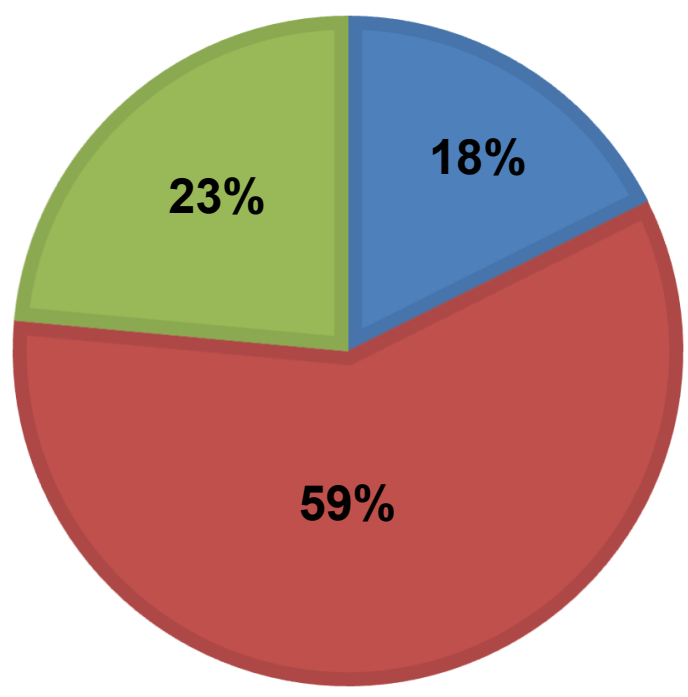

Fonte: Gráfico elaborado pelas Autoras a partir de dados coletados na pesquisa. 
De acordo com o gráfico 1 é possível constatar que a maioria dos docentes (59\%) possui entre cinco e dez anos de experiência na docência do Ensino Superior. Morosini (2000) sinaliza que o professor universitário, na última década, sofre uma marcante pressão, advinda da legislação e imposta pela instituição e buscada por ele, para sua qualificação de desempenho, no qual o didático passa a ocupar um papel de destaque.

GRÁFICO 2: Opinião dos professores sobre a satisfação em relação ao trabalho.

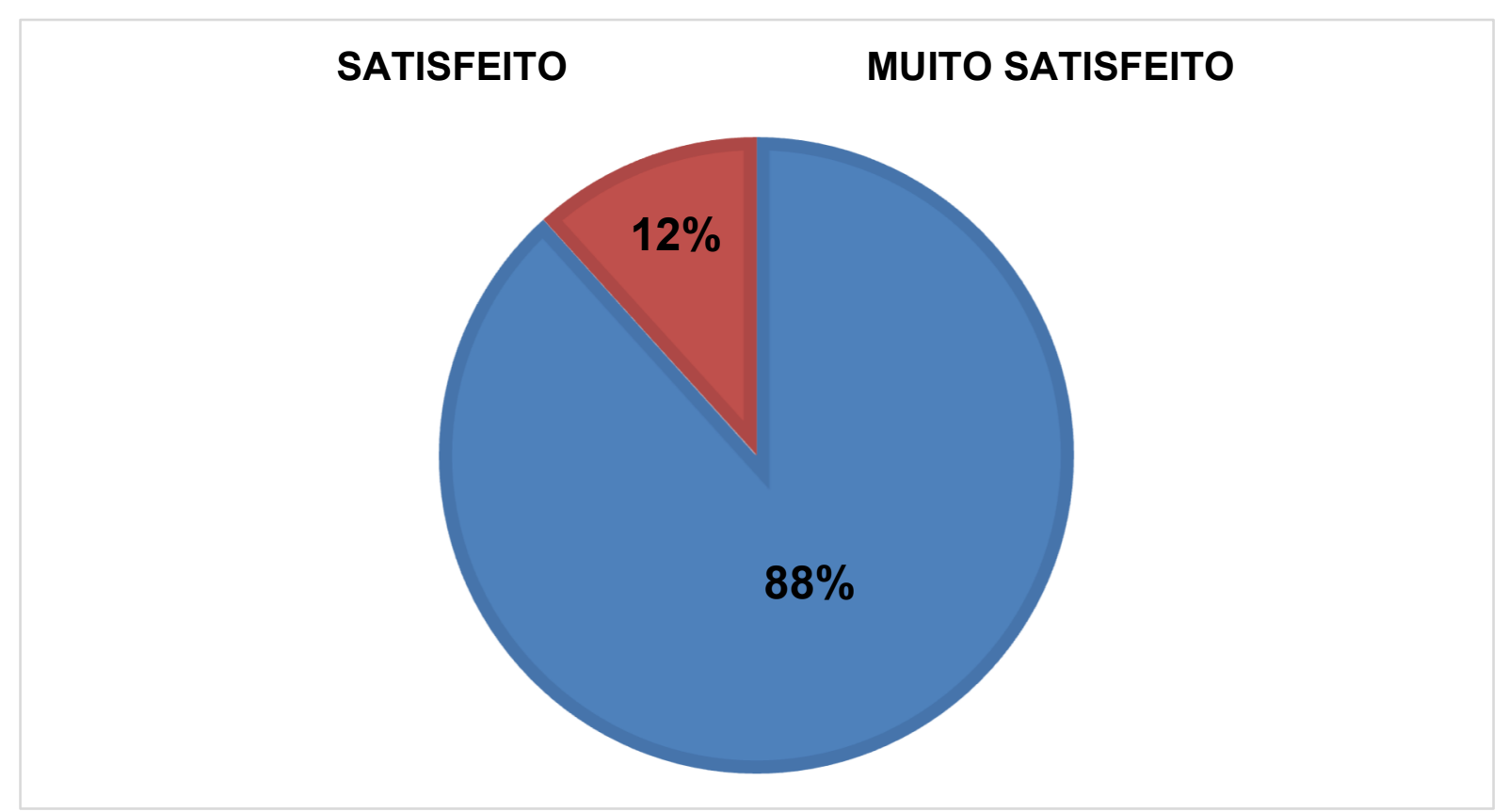

Fonte: Gráfico elaborado pelas Autoras a partir de dados coletados na pesquisa.

Quando se pensa em qualidade de vida muitos aspectos devem ser considerados, especialmente ao considerar o ambiente de trabalho. Nesse sentido, é importante destacar que professores de ensino superior são expostos a uma série de exigências e cargas de trabalhos que acarretam problemas em diversos aspectos, desde sua atuação no ambiente acadêmico até prejuízos em suas relações sociais e familiares. Neste contexto, as jornadas longas de trabalho, que exigem mais tempo, rapidez, atenção e possuem tarefas complexas podem causar sobrecarga ou exaustão. (GIANASES e BORGES, 2009). 
Sabendo que os professores de ensino superior têm grande responsabilidade na formação acadêmica de estudantes, é importante que seu rendimento seja satisfatório. Assim, vale lembrar que os aspectos emocionais afetam diretamente a vida profissional do indivíduo, nos professores, por exemplo, pode haver prejuízos em seu planejamento, tornando suas aulas pouco estimulantes e criativas, acarretando até mesmo uma relação conflituosa com os alunos (CARLOTTO, 2002).

As mudanças que têm ocorrido no mundo do trabalho, como, por exemplo, o processo de globalização da economia, as novas tecnologias, a grande competição no mercado de trabalho, a necessidade de se produzir mais e mais rápido evitando desperdícios, entre muitos outros fatores, acabam gerando um desgaste físico e emocional nos trabalhadores (SILVA, 2010, p. 95).

GRÁFICO 3: Atuação dos professores em outra função além da docência.

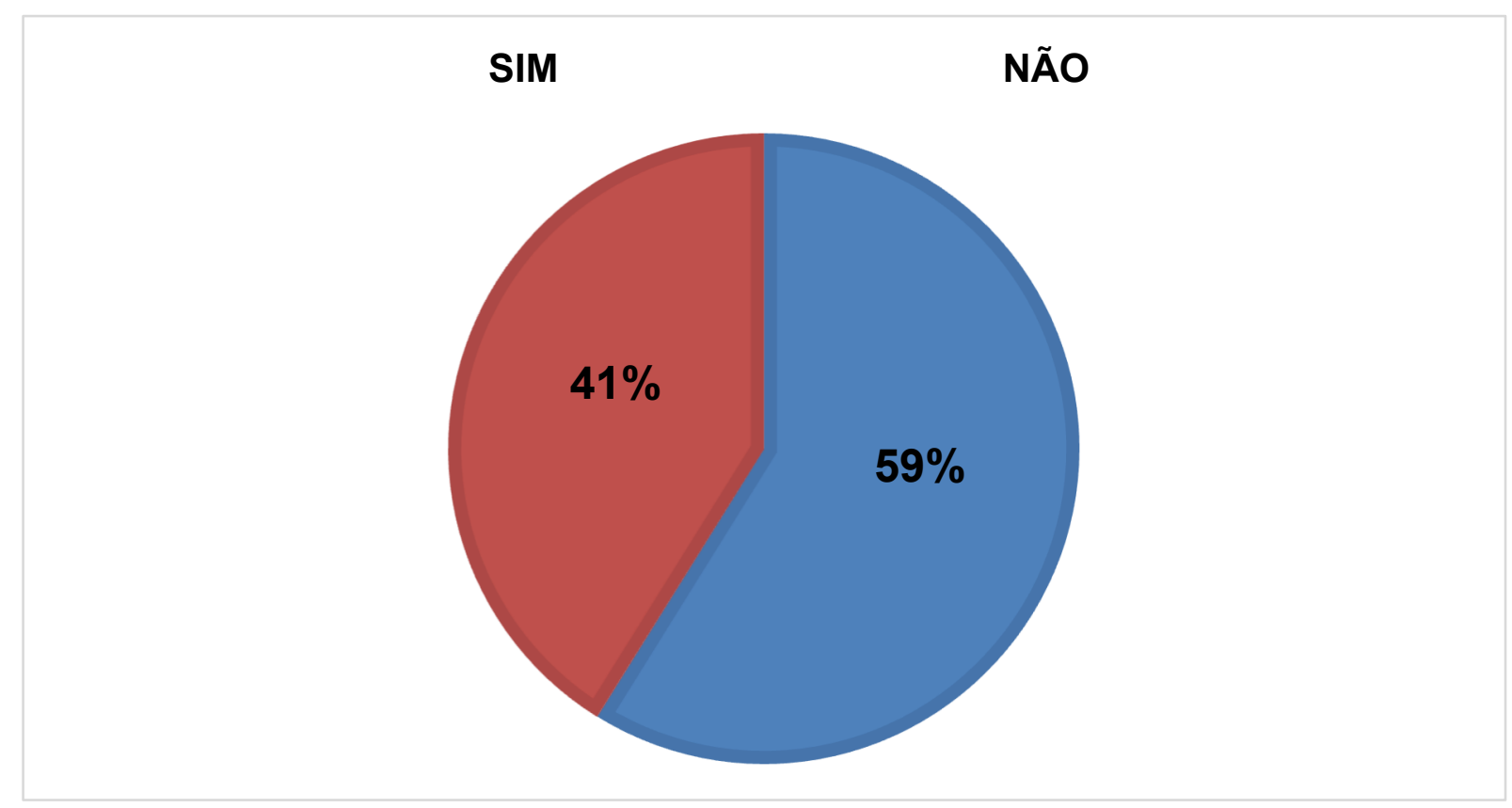

Fonte: Gráfico elaborado pelas Autoras a partir de dados coletados na pesquisa.

De acordo com os dados coletados, foi possível observar que a maioria dos entrevistados (59\%) não desenvolve outra atividade além da docência no Ensino Superior. Partindo desse contexto, é possível evidenciar Dejours (1991) o qual deixa claro em suas discussões que o trabalho ocupa grande parte do tempo na vida das pessoas e que por isso ele deveria ser a principal fonte de realização, contudo, nem 
sempre isso acontece, levando a pessoa a um estado de estresse e insatisfação por um período longo de tempo. Logo, ao invés de ver o trabalho como algo que acrescenta, ocorre a fuga e o desejo de acabar com o mesmo.

No ensino superior, em virtude da grande carga de trabalho, em especial daqueles que atuam em dois ou mais locais diferentes, ocorrem prejuízos na qualidade de vida dos professores, os quais podem desenvolver até mesmo psicopatologias.

Embora a pesquisa na IES não tenha identificado problemas graves na qualidade de vida dos professores, é importante destacar que é fundamental que haja a satisfação no trabalho e além disso que o indivíduo consiga conciliar seu tempo com a família e o lazer, a fim de evitar que as tarefas consideradas estressantes interfiram em suas relações e especialmente em sua saúde mental.

Nesse cenário é preponderante que haja uma atenção especial aos docentes de modo geral, já que a sobrecarga de trabalho, os baixos salários ou pouco reconhecimento podem ter influencias diretas em seu desempenho profissional. Assim, destaca-se que os professores muitas vezes passam por problemas emocionais que atrapalham seus planejamentos e ações.

Sentir prazer no trabalho, é de fundamental importância, considerando que a satisfação no trabalho e a capacidade para o trabalho são fundamentais para todo trabalhador. "Uma maior satisfação no trabalho, sem ansiedade e sem medo, faz com que o trabalhador encontre significado em sua atividade laboral e apresente atitudes positivas de enfrentamento à vida." (MARQUEZE e MORENO, 2009, p. 01).

Ainda estes autores explicam que principalmente na profissão docente, a boa saúde mental e emocional é de suma importância para que o professor realize seu trabalho com qualidade, pois, os professores enfrentam eventualmente situações que afetam seu bem estar e consequentemente sua qualidade de vida.

Isto posto, observando os aspectos tratados nesta pesquisa, ficou evidente que na Instituição pesquisada os professores de modo geral estão satisfeitos com suas carreiras com seus salários e atividades laborais, contudo não se pode negligenciar estes aspectos, mesmo quando as respostas são positivas, tendo em vista que a qualidade de vida é um conjunto de aspectos a serem considerados de 
modo a garantir que os doentes tenham verdadeiramente satisfação em suas atividades.

\section{CONSIDERAÇÕES FINAIS}

De todas as profissões que existem, a docência é a mais desafiadora de todas, pois na maioria das profissões que tem contato com pessoas, o profissional dificilmente atende ou se ocupa com mais de trinta indivíduos, ao mesmo tempo, no mesmo lugar e com várias turmas. Portanto, quando entra nas salas de aula, o professor tem que lidar com dimensões, perspectivas, expectativas e dinâmicas de vida as mais diversas. Ter competência técnico-científica séria, nesse caso, apenas um aspecto das tarefas que precisa ou poderia desempenhar. No entanto, além de lidar com a rotina e obstáculos da sala de aula, ainda há a rotina fora do ambiente acadêmico que também exige muito do ser humano. Para ter uma vida melhor é preciso estar com a saúde em dia. E ao falar de saúde não se deve pensar apenas numa abrangência física. $O$ organismo humano é um todo composto por aspectos fisiológicos, mentais, emocionais e espirituais.

Ter um hobby, fazer uma atividade física, sair com os amigos ou com a família, todos esses são hábitos que geram satisfação e vontade de desfrutar bem os prazeres da vida. O termo qualidade de vida continua na ordem do dia e representa um desafio para muitas pessoas garantir condições de vida que englobe a saúde física, mental e espiritual, além de equilíbrio entre o lado pessoal e profissional. Então, podemos perceber que o docente necessita ter metas e objetivos, planejar o seu futuro, participar de decisões pessoais, familiares e sociais, não deixar de ter atividades intelectuais, físicas, ler muito, fazer cursos, estar sempre por dentro dos assuntos que acontecem ao seu redor e em sua vida social. 


\section{REFERÊNCIAS BIBLIOGRÁFICAS}

BARDIN, Laurence. Análise de Conteúdo. 70. ed. Presses Universitaires de France, 1977.

CARLLOTO, Mary Sandra. A Síndrome de Burnout e o trabalho docente. Psicologia em estudo. V. 07. Jan-jun. 2002.

CHAN, Dr. Margaret. Organização Mundial de Saúde.

CHIAVENATO, Idalberto. Gestão de Pessoas: o novo papel dos recursos humanos nas organizações. 4. ed. Barueri-SP: Manole, 2014.

COSTA, W. S. Resgate da humanização no ambiente de trabalho. Caderno de Pesquisas em Administração, São Paulo: PPGA/FEA/USP, v. 09, n. 2, p. 13-23, abr. -jun. 2002.

DEJOURS, C. A loucura do trabalho. São Paulo: Cortez, 1991.

FERREIRA, Patrícialtala. Clima Organizacional e qualidade de vida no trabalho. [Reimpr.]. Rio de Janeiro: LTC, 2014.

GIANASES, Luciana Bezerra de Souza; BORGES, Lívia de Oliveira. Sindrome de Burnout no setor de transporte de Natal. Psicologia: teoria e pesquisa. V.25. n.03. jul-set,2009.

GIL, Antonio Carlos. Como Elaborar Projetos de Pesquisa. 5. ed. São Paulo: Atlas, 2010.

MAXIMIANO, Antonio Cesar Amaru. Recursos Humanos: estratégia e gestão de pessoas na sociedade global. 1. ed. Rio de Janeiro: LTC, 2014.

MARQUEZE, Elaine Cristina; MORENO, Claudia Roberta de Castro. Satisfação no trabalho e capacidade entre docentes universitários. Psicologia em estudo. V.14. jan-mar. Maringá:2009.

MOROSINI, Marilia Costa (Org.). Professor do ensino superior: identidade, docência e formação. Brasília: Instituto Nacional de Estudos e Pesquisas Educacionais, 2000. 